Supporting Information for

\title{
A Post-Functionalizable Iso-Polyoxotitanate Cage Cluster
}

Jie Hou, Junyi Hu, Qing Sun, Guanyun Zhang, Chen-Ho Tung, Yifeng Wang*

Key Lab of Colloid and Interface Science of the Education Ministry, Department of Chemistry and Chemical Engineering, Shandong University, Ji'Nan 250100, P. R. China

\section{Table of contents}

S1. Experimental section

S2. Structure and Characterization data

Table S1. Elementary analysis data

Table S2. Crystallographic data

Table S3. Bond valence sum (BVS) calculations

Figure S1. ESR spectra

Figure S2. XPS data

Figure S3. FTIR spectra

Figure S4. Structures of compounds $1 \mathrm{a}$ and $\mathbf{2 a}$

Figure S5. Powder X-ray diffraction patterns

Figure S6. Comparison of the dimensions of $\left[\left(\mathrm{ClO}_{4}\right) @ \mathrm{HV}_{8}^{\mathrm{IV}} \mathrm{V}_{14}^{\mathrm{V}}\left(\mu_{2}-\mathrm{O}\right)_{32}\left(\mathrm{O}_{t}\right)_{22}\right]^{6-}(\mathbf{6 a})$ with 3a

Figure S7. Illustration of reaction of 3a with two equivalents of $\mathrm{H}_{2} \mathrm{DTBC}$

More description of compound 5

Figure S8. FTIR of compound $\mathbf{3}$ treated with various solvents

Figure S9. ${ }^{13} \mathrm{C}$ NMR of compound 3 in $\mathrm{CDCl}_{3}$

Figure S10. ${ }^{13} \mathrm{C}$ NMR of compound 4 in $\mathrm{CDCl}_{3}$

Figure S11. UV-vis of compound $\mathbf{3}$ in isopropanol and solid state diffuse reflectance spectrum

Figure S12. UV-vis of compound 3 in isopropanol and calculations of the band gaps

Figure S13. UV-vis of compound 4 in isopropanol

Figure S14. UV-vis of compound 4 in isopropanol and calculations of the band gaps

\section{S1. Experimental section}

Chemicals. $\mathrm{Ti}\left(\mathrm{O}^{i} \mathrm{Pr}\right)_{4}$ was purchased from Aldrich, $\mathrm{TiI}_{4}$ was obtained from Alfa Aesar, 3,5-di-tertbutylcatechol $\left(\mathrm{H}_{2} \mathrm{DTBC}\right)$ was obtained from Alfa. The reagents were used as received. All the solvents were carefully dried by distillation with $\mathrm{CaO}$ before use.

Syntheses. All the moisture sensitive materials were handled in a glovebox in which $\mathrm{H}_{2} \mathrm{O}$ concentration is lower than $0.1 \mathrm{ppm}$. Solvent evaporation was also conducted in the glovebox.

Synthesis of $\left[\mathrm{Ti}_{3}\left(\mathrm{O}^{i} \mathrm{Pr}\right)_{11}\right]\left(\mathrm{I}_{3}\right)(\mathbf{1}),\left[\mathrm{Ti}_{12} \mathrm{O}_{14}\left(\mathrm{O}^{i} \mathrm{Pr}\right)_{18}\right]\left(\mathrm{I}_{3}\right)_{2}(\mathbf{2}),\left[\mathrm{I} @ \mathrm{Ti}_{22}\left(\mu_{2}-\mathrm{O}\right)_{7}\left(\mu_{3}-\mathrm{O}\right)_{24}\left(\mu_{3}-\mathrm{OH}\right)\left(\mu_{1}-\mathrm{O}^{i} \mathrm{Pr}\right)_{22}\left(\mu_{2^{-}}\right.\right.$ $\left.\left.\mathrm{O}^{i} \mathrm{Pr}\right)\right]\left(\mathrm{I}_{3}\right)(3)$. To a $23 \mathrm{~mL}$ Teflon-lined Parr bomb were added $1.0 \mathrm{~g} \mathrm{Ti}(\mathrm{OPr})_{4}(3.50 \mathrm{mmol}), 0.28 \mathrm{~g}$ TiI $4(0.50$ $\mathrm{mmol}$ ), and $16 \mathrm{~mL}$ of isopropanol. The bomb was sealed and then placed in $100{ }^{\circ} \mathrm{C}$ oven for various period. After slowly cooling to room temperature $\left(2{ }^{\circ} \mathrm{C} \mathrm{h}^{-1}\right)$, dark-red solutions with or without dark-red crystals were obtained. The solutions were transferred to gas-tight vials to stand at room temperature. After a few days, darkred crystals of the desired products were received. Compound $\mathbf{1}$ was formed after one or two days solvothermal 
reactions at $100^{\circ} \mathrm{C}$, and was obtained after aging the reaction solution. Its highest yield was $5 \%$ based on Ti. The low yield may be associated with its high solubility in isopropanol, and/or the possible dissociation into monomers. Compound $\mathbf{2}$ was formed in two-day reactions and may be obtained immediately after cooling the reaction solution to room temperature. If not, $\mathbf{2}$ could form after standing for one day. It was collected by filtration and the highest yield was $10 \%$ based on Ti. After removing $\mathbf{2}$, from the filtrate compound $\mathbf{3}$ crystalized as dark-red crystals after aging. Its highest yield was obtained in a five-day reaction and was $80 \%$ based on Ti.

Synthesis of $\left[\mathrm{I} @ \mathrm{Ti}_{22}\left(\mu_{2}-\mathrm{O}\right)_{6}\left(\mu_{3}-\mathrm{O}\right)_{24}\left(\mu_{2}-\mathrm{OH}\right)_{2}\left(\mu_{1}-\mathrm{O}{ }^{i} \mathrm{Pr}\right)_{20}(\mathrm{DTBC})_{2}\right]\left(\mathrm{I}_{3}\right)(\mathbf{4})$. In a $5 \mathrm{~mL}$ vial, $100 \mathrm{mg}$ compound 3 $(29.1 \mu \mathrm{mol})$ was dissolved in $3 \mathrm{~mL}$ of isopropanol. Then, $\mathrm{H}_{2} \mathrm{DTBC}(58.2 \mu \mathrm{mol})$ in $100 \mu \mathrm{L}$ of isopropanol was added to give a dark-red solution. This solution was allowed to evaporate slowly in the glovebox and yielded dark-red crystals of $\mathbf{4}$. Yield was $41 \%$ based on compound $\mathbf{3}$.

Synthesis of $\left[\mathrm{I} @ \mathrm{Ti}_{22}\left(\mu_{2}-\mathrm{O}\right)_{11}\left(\mu_{3}-\mathrm{O}\right)_{20}\left(\mu_{1}-\mathrm{O}^{i} \mathrm{Pr}\right)_{16}\left(\mu_{2}-\mathrm{O}^{i} \mathrm{Pr}\right)_{2}\left({ }^{t} \mathrm{BuCOO}\right)_{9}\left(\mathrm{OH}_{2}\right) \mathrm{H}_{3}\right]\left(\mathrm{I}_{3}\right) \cdot \mathrm{HO}{ }^{i} \operatorname{Pr}(\mathbf{5})$. In a $5 \mathrm{~mL}$ glass vial, $100 \mathrm{mg}$ compound $3(29.1 \mu \mathrm{mol})$ was dissolved in $3 \mathrm{~mL}$ isopropanol. Pivalic acid solution of (262 $\mu \mathrm{mol}$ in $100 \mu \mathrm{L}$ of isopropanol) was added to the mixture. This solution was allowed to evaporate slowly in the glovebox and yielded dark-red crystals of $\mathbf{5}$. Yield was $49 \%$ based on compound $\mathbf{3}$.

Characterization. Elemental analyses $(\mathrm{C}, \mathrm{H})$ were obtained by a FLASH EA1112 elemental analyzer. UVVis absorption spectra were measured on Agilent Cary 60 spectrophotometer. X-ray photoelectron spectroscopy (XPS) spectra were recorded using the Omicron (ESCA+) spectrometer using an Al Ka source (1486.6 eV). Electron spin resonance (ESR) measurements were performed on a Bruker ESR E500 instrument. ${ }^{1} \mathrm{H}$ NMR and ${ }^{13} \mathrm{C}$ NMR spectra were obtained using the Bruker $400 \mathrm{MHz}$ Fourier transform NMR spectrometer in $5 \mathrm{~mm}$ NMR tubes. Single crystal X-ray diffraction data were collected using a Bruker SMART APEX II diffractometer with graphite-monochromated Mo-K $\alpha$ radiation source $(\lambda=0.71073 \AA)$ at $173 \mathrm{~K}$. X-ray powder diffractions were conducted with a Bruker D8 Advance $\mathrm{X}$-ray diffraction instrument using $\mathrm{Cu}-\mathrm{K} \alpha$ radiation (40KV and $40 \mathrm{~mA}$ )

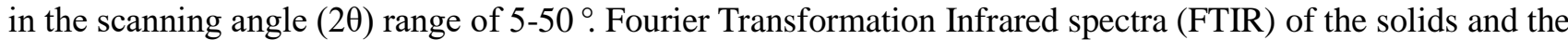
solution samples were recorded using a PerkinElmer Spectrum Two IR Spectrometer. UV-vis diffuse reflectance spectra (DRS) were measured on a Shimadzu UV2550 spectrophotometer with $\mathrm{BaSO}_{4}$ as the reflectance standard. Raman spectra were obtained on a NEXUS 670 FT-IR Raman spectrometer with $532 \mathrm{~nm}$ excitation. A commercial thermo-hygrometer was used to record the ambient temperature and humidity.

Single crystal X-ray crystallography. The crystals were mounted in a nitrogen flow as quickly as possible. Data reduction was performed with the SAINT software, ${ }^{1}$ absorption correction was applied with SADABS program, ${ }^{2}$ and the structure solution and refinement were done using the Olex 2 v1.2 program ${ }^{3}$ with the embedded SHELXL package. Hydrogen atoms of the organic ligands were added theoretically.

\section{S2. Structure and Characterization data}

Table S1. Elementary analysis data

\begin{tabular}{|c|c|c|c|c|}
\hline Compound & Appearance & Formula & Anal. Calcd. & Anal. Found \\
\hline 1 & dark red, block crystal & {$\left[\mathrm{Ti}_{3}\left(\mathrm{O}^{i} \mathrm{Pr}\right)_{11}\right]\left(\mathrm{I}_{3}\right)$} & - & - \\
\hline 2 & dark red, tiny crystal & {$\left[\mathrm{Ti}_{12} \mathrm{O}_{14}\left({ }^{i} \mathrm{OPr}\right)_{18}\right]\left(\mathrm{I}_{3}\right)_{2}$} & $\mathrm{C}, 24.7 ; \mathrm{H}, 4.8$ & C, $24.8 ;$ H 5.1 \\
\hline 3 & dark red, block crystal & {$\left[\mathrm{I} @ \mathrm{Ti}_{22} \mathrm{O}_{32}\left(\mathrm{O}^{i} \mathrm{Pr}\right)_{23} \mathrm{H}\right]\left(\mathrm{I}_{3}\right)$} & $\mathrm{C}, 24.1 ; \mathrm{H}, 4.7$ & C, $22.5 ; \mathrm{H} 4.5$ \\
\hline 4 & dark red, small crystal & {$\left[\mathrm{I} @ \mathrm{Ti}_{22} \mathrm{O}_{30}\left(\mu_{2}-\mathrm{OH}\right)_{2}\left(\mathrm{O}^{i} \mathrm{Pr}\right)_{20}(\mathrm{DTBC})_{2}\right]\left(\mathrm{I}_{3}\right)$} & C, $28.6 ; H, 4.9$ & C, $27.6 ;$ H 4.9 \\
\hline 5 & dark red, block crystal & {$\left[\mathrm{I} @ \mathrm{Ti}_{22} \mathrm{O}_{31}\left(\mathrm{O}^{i} \mathrm{Pr}\right)_{18}\left({ }^{t} \mathrm{BuCOO}\right)_{9}\left(\mathrm{OH}_{2}\right) \mathrm{H}_{3}\right]\left(\mathrm{I}_{3}\right)$} & C, $29.8 ; H, 5.3$ & C, 29.1; H 5.4 \\
\hline
\end{tabular}

1. SaintPlus: Data Reduction and Correction Program, version 6.22; Bruker AXS: Madison, WI, 2001.

2. Sheldrick, G. M. SADABS, A Program for Empirical Absorption Correction; University of Göttingen: Göttingen, Germany, 1998.

3. Dolomanov, O. V.; Bourhis, L. J.; Gildea, R. J.; Howard, J. A. K.; Puschmann, H., OLEX2: a complete structure solution, refinement and analysis program. J. Appl. Cryst. 2009, 42, (2), 339-341. 
Table S2. Crystallographic data of compounds 1-5

\begin{tabular}{|c|c|c|c|c|c|}
\hline Compound & 1 & 2 & 3 & 4 & 5 \\
\hline Formula unit & $\mathrm{C}_{33} \mathrm{H}_{77} \mathrm{I}_{3} \mathrm{O}_{11} \mathrm{Ti}_{3}$ & $\mathrm{C}_{54} \mathrm{H}_{126} \mathrm{I}_{6} \mathrm{O}_{32} \mathrm{Ti}_{12}$ & $\mathrm{C}_{69} \mathrm{H}_{162} \mathrm{I}_{4} \mathrm{O}_{55} \mathrm{Ti}_{22}$ & $\mathrm{C}_{88} \mathrm{H}_{180} \mathrm{I}_{4} \mathrm{O}_{56} \mathrm{Ti}_{22}$ & $\mathrm{C}_{102} \mathrm{H}_{220} \mathrm{I}_{4} \mathrm{O}_{69} \mathrm{Ti}_{22}$ \\
\hline Formula weight (g/mol) & 1174.35 & 2623.7 & 3433.37 & 3695.71 & 4118.48 \\
\hline Crystal system & trigonal & monoclinic & monoclinic & triclinic & monoclinic \\
\hline Space group (Nr.) & $\mathrm{R}-3 \mathrm{c}$ & $\mathrm{P} 2{ }_{1} / \mathrm{c}$ & $\mathrm{P} 2{ }_{1} / \mathrm{c}$ & $\mathrm{P}-1$ & $\mathrm{P} 2{ }_{1} / \mathrm{n}$ \\
\hline $\mathrm{a}(\AA)$ & $13.102(2)$ & $15.0141(14)$ & $28.2087(7)$ & $19.322(7)$ & $18.3241(10)$ \\
\hline $\mathrm{b}(\AA)$ & $13.102(2)$ & $51.767(5)$ & $17.5165(5)$ & $26.242(10)$ & $30.6429(18)$ \\
\hline$c(\AA)$ & $49.573(16)$ & $38.161(4)$ & $27.5141(7)$ & $31.425(12)$ & $30.9343(18)$ \\
\hline$\alpha\left(^{\circ}\right)$ & 90 & 90 & 90 & $95.039(4)$ & 90 \\
\hline$\beta\left(^{\circ}\right)$ & 90 & $97.7200(10)$ & $100.6100(10)$ & $90.200(4)$ & $95.403(3)$ \\
\hline$\delta\left({ }^{\circ}\right)$ & 120 & 90 & 90 & $107.814(4)$ & 90 \\
\hline Volume $\left(\AA^{3}\right)$ & $7369(3)$ & $29392(5)$ & $13362.8(6)$ & $15103(10)$ & $17292.5(17)$ \\
\hline $\mathrm{Z}$ & 6 & 4 & 4 & 2 & 4 \\
\hline $\operatorname{Density}_{\text {calc }}\left(\mathrm{g} / \mathrm{cm}^{3}\right)$ & 1.483 & 1.779 & 1.706 & 1.625 & 1.581 \\
\hline Abs. Coeff. $\mu\left(\mathrm{mm}^{-1}\right)$ & 2.402 & 2.876 & 2.231 & 1.981 & 1.753 \\
\hline Temperature (K) & 173 & 173 & 173 & 173 & 173 \\
\hline Total reflections & 8755 & 172152 & 130141 & 197173 & 141889 \\
\hline $\operatorname{Min}-\max \theta\left(^{\circ}\right)$ & 4.868 to 54.926 & 4.784 to 54.97 & 1.468 to 55.006 & 4.374 to 55.308 & 1.874 to 50 \\
\hline Unique reflections & 8061 & 171053 & 127068 & 197173 & 123191 \\
\hline $\begin{array}{l}\text { Calculated reflection }(\mathrm{I}> \\
2 \sigma)\end{array}$ & 1203 & 25832 & 22459 & 31634 & 17601 \\
\hline $\mathrm{R}_{1}[\mathrm{I}>=2 \sigma]^{\mathrm{a}}$ & 0.1035 & 0.0971 & 0.0576 & 0.1486 & 0.0852 \\
\hline $\mathrm{wR}_{2}(\text { all data })^{\mathrm{b}}$ & 0.3512 & 0.2687 & 0.1634 & 0.4092 & 0.1610 \\
\hline $\mathrm{R}_{\text {int }}$ & 0.0233 & 0.1126 & 0.0323 & 0.1132 & 0.0579 \\
\hline Goodness of fit on $\mathrm{F}^{2}$ & 1.078 & 1.024 & 1.058 & 1.072 & 1.1230 \\
\hline Parameters ${ }^{b}$ & 85 & 2711 & 1422 & 2826 & 1839 \\
\hline Restraints & 0 & 92 & 33 & 90 & 483 \\
\hline $\begin{array}{l}\text { Largest diff. peak/hole (e } \\
\AA^{-3} \text { ) }\end{array}$ & $1.84 /-2.21$ & $3.13 /-1.88$ & $3.29 /-2.58$ & $5.02 /-2.00$ & $1.51 /-1.30$ \\
\hline
\end{tabular}


Table S3. Bond valence sum (BVS) calculations of the $\mathrm{O}_{\text {in }}$ atoms of $\mathbf{3 a}$ and $\mathbf{4 a}$, which indicates the $O_{\text {in }}$ atoms must be protonated.

\begin{tabular}{lllll}
\hline Oxygen & Titanium & Bond length, A & Bond valence & BVS \\
\hline $\mathrm{O}_{\text {in }}$ of 3a, as shown below & $\mathrm{Ti}_{1}$ & 2.138 & 0.417 & 0.954 \\
$\mathrm{Ti}_{2}$ & 2.15 & \\
& $\mathrm{Ti}_{3}$ & 2.56 & 0.404 & \\
& & & \\
& & & \\
& & & \\
\end{tabular}
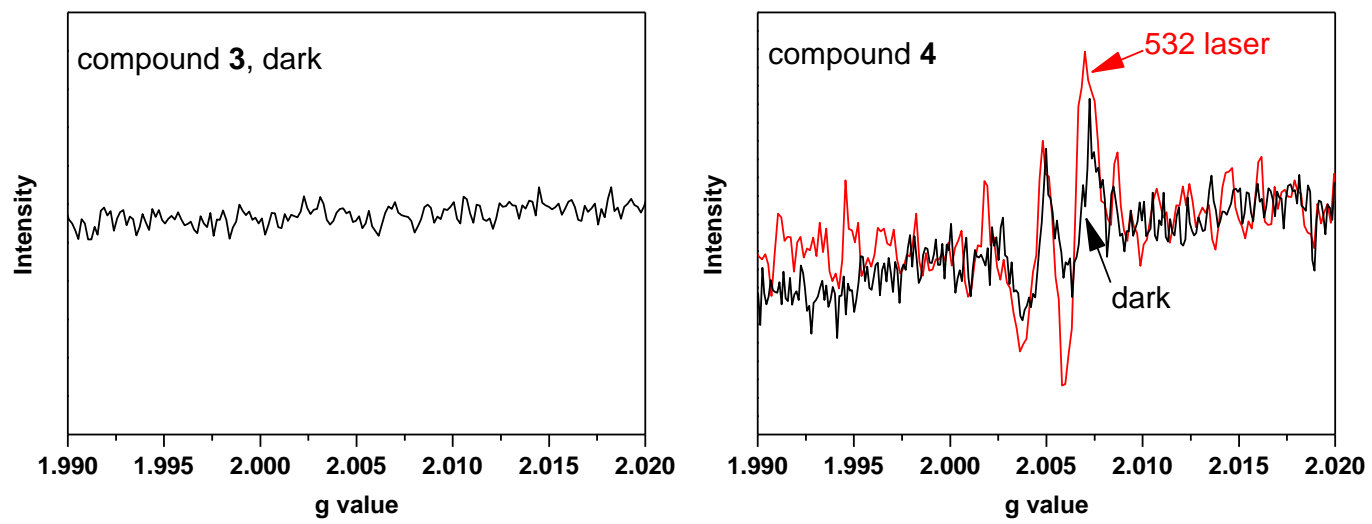

Figure S1. ESR spectra of compound 3 (left) and 4 (right) at ca. 293 K. Compound 3 (left) shows no ESR signals, compound 4 (right) shows signals both in dark (black) and after 45-s 532-nm laser irradiation (red). 


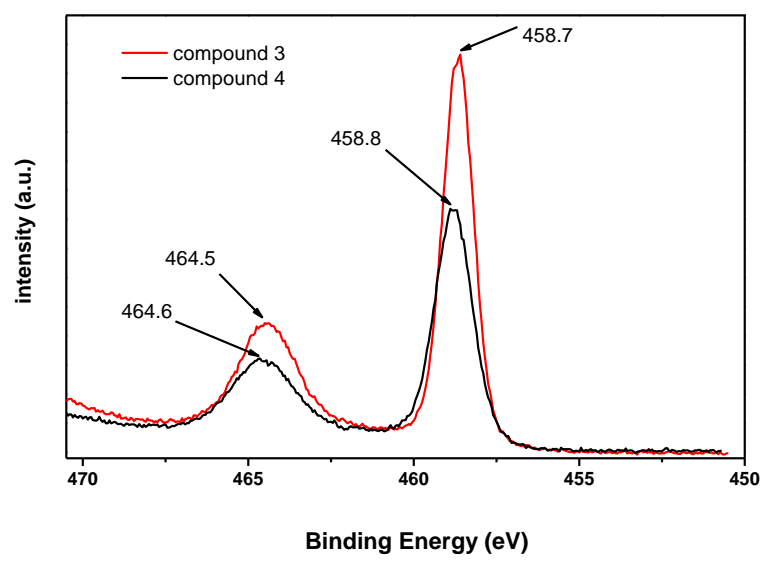

Figure S2. XPS data of compounds 3 and 4. Error of XPS can be $\pm 0.1 \mathrm{eV}$. The $\mathrm{BE}$ of $\mathrm{Ti} 2 \mathrm{p} 1 / 2$ of $\mathrm{TiO}_{2}$ is 464.5 $\mathrm{eV}$. The BEs of Ti2p1/2 and Ti2p3/2 indicate that the Ti-atoms of both $\mathbf{3}$ and $\mathbf{4}$ are in the +4 oxidation state.
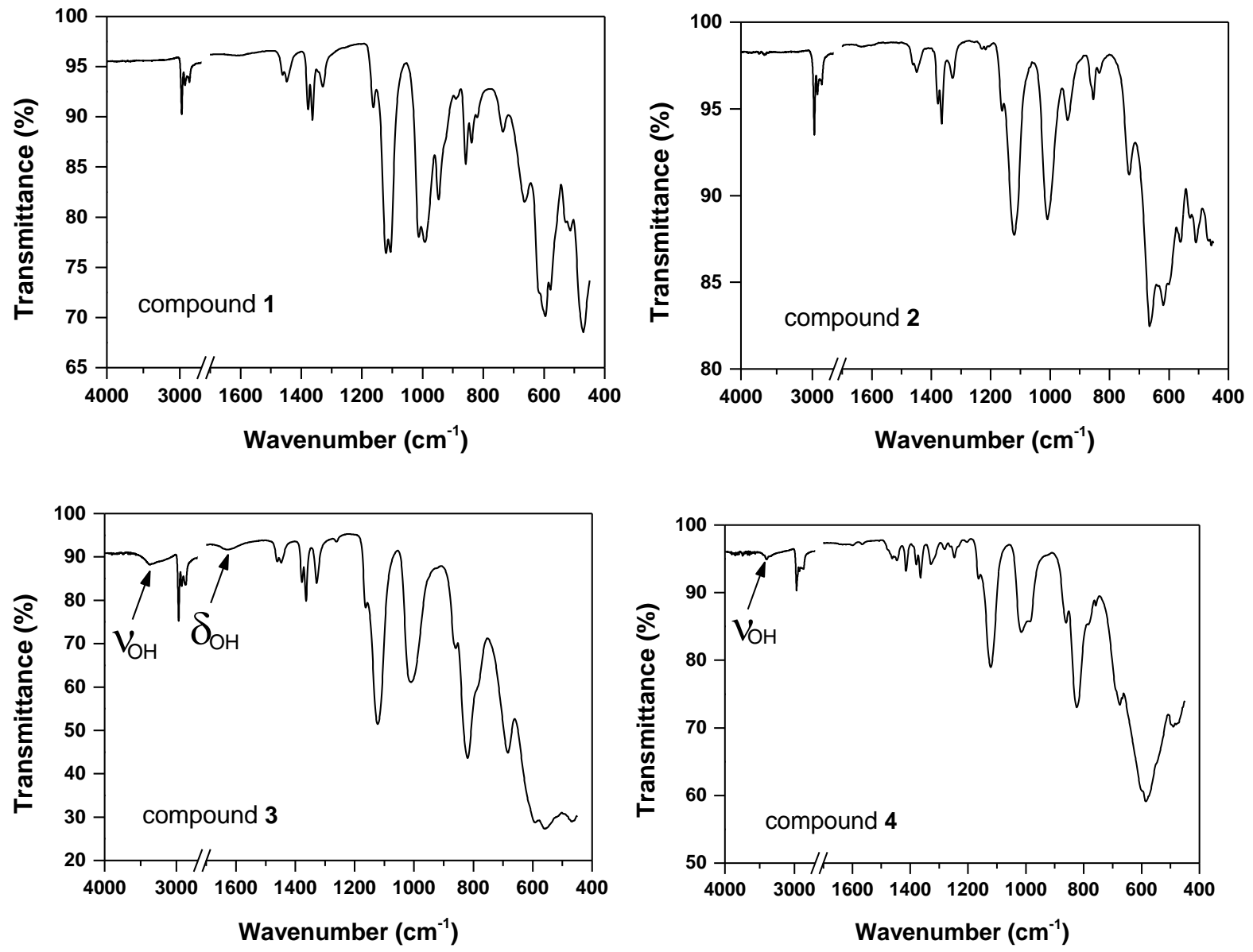

Figure S3. FTIR of compounds 1-4. 


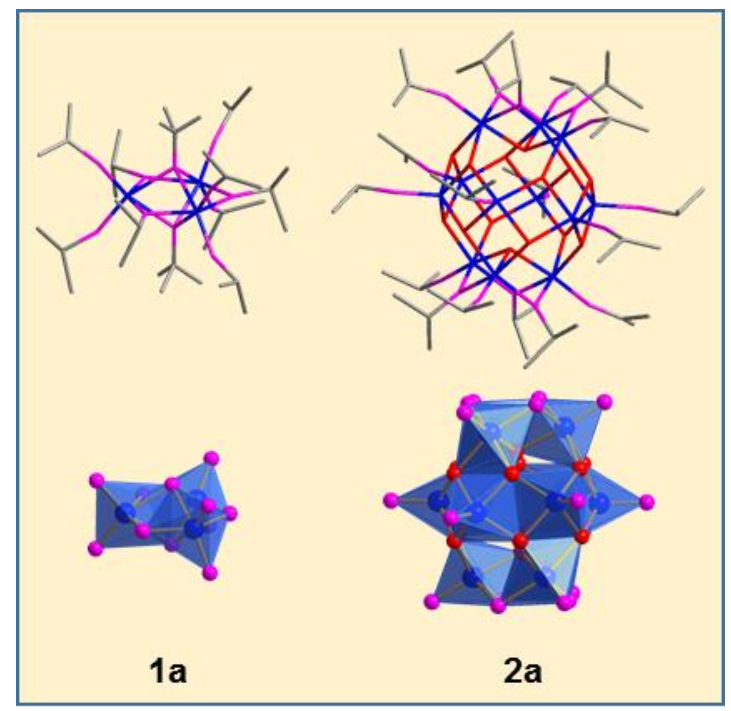

Figure S4. Structures of compounds 1a and 2a.
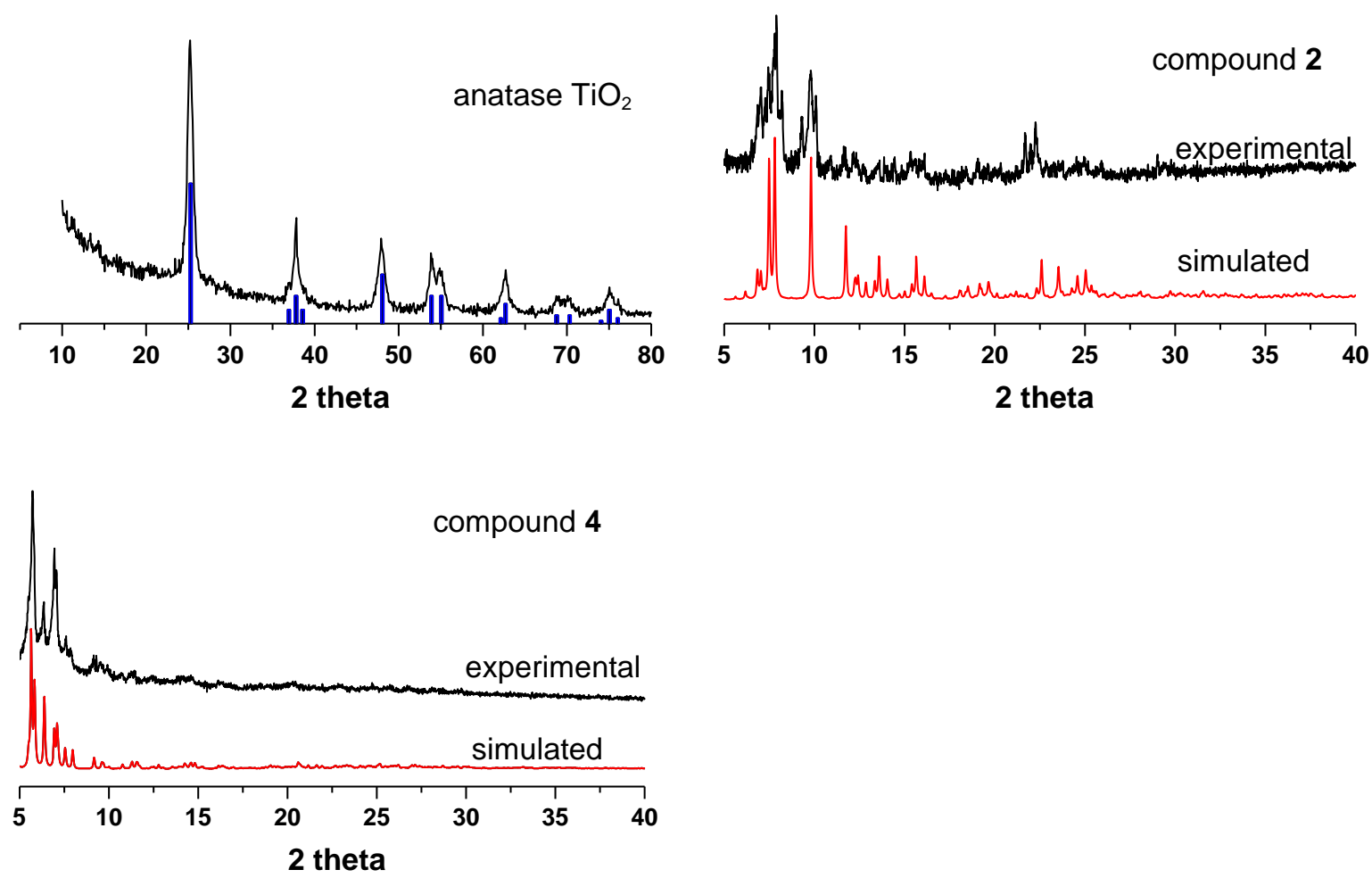

Figure S5. Powder X-ray diffraction patterns of $\mathrm{TiO}_{2}$, compounds 2 and $\mathbf{4}$. The $\mathrm{TiO}_{2}$ sample was obtained by reaction of $\mathrm{TiX}_{4}$ and $\mathrm{Ti}\left(\mathrm{O}^{i} \mathrm{Pr}\right)_{4}$ in isopropanol at $150{ }^{\circ} \mathrm{C}$ for 3 days; a small amount of the same type of $\mathrm{TiO}_{2}$ precipitate was also formed at $100{ }^{\circ} \mathrm{C}$ after two weeks reaction. The XRD pattern indicates the as-prepared $\mathrm{TiO}_{2}$ is anatase, by comparing to the authentic pdf card 21-1276. 

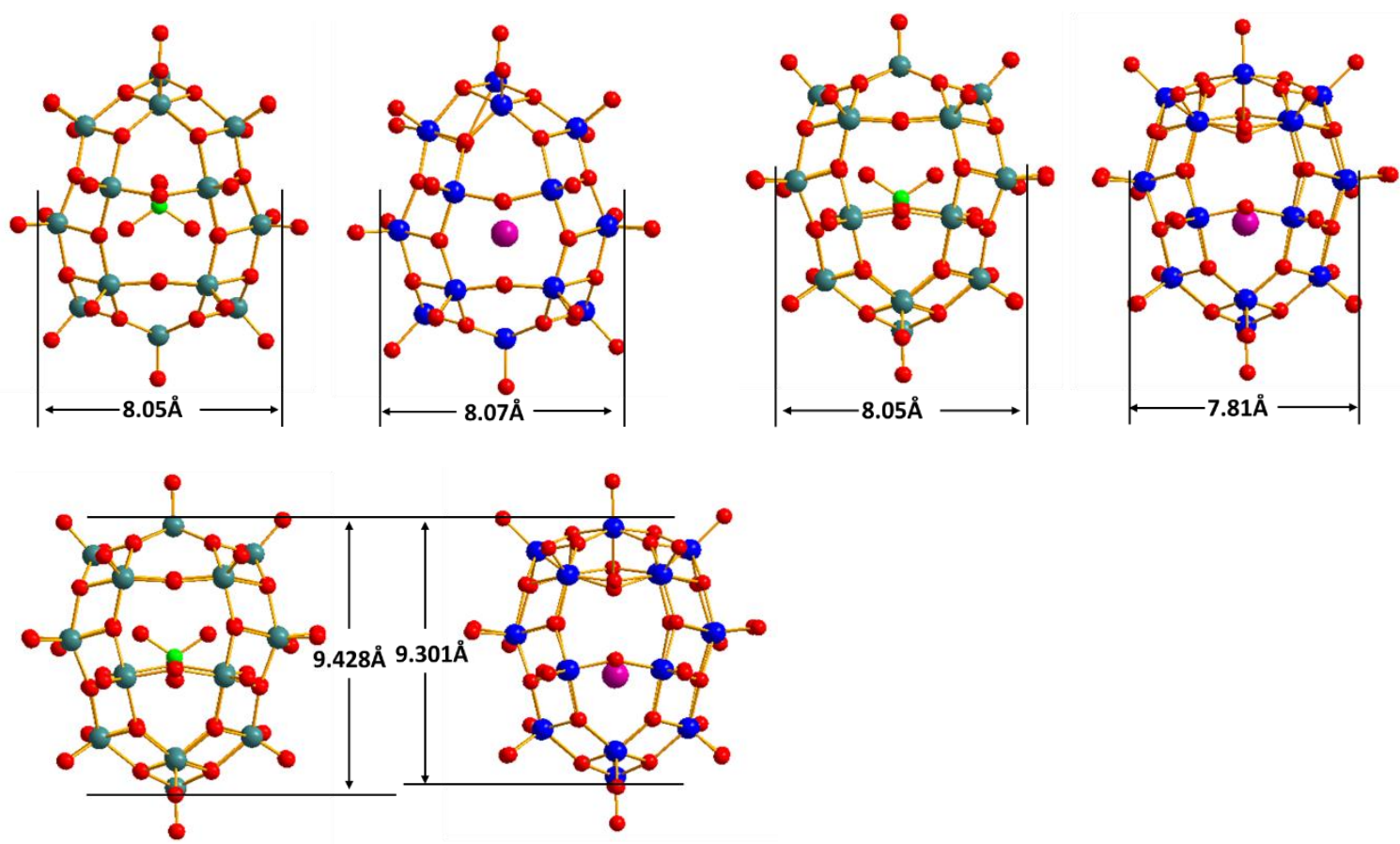

Figure S6. Comparison the dimensions of $\left[\left(\mathrm{ClO}_{4}\right) @ \mathrm{HV}_{8}^{\mathrm{IV}} \mathrm{V}_{14}^{\mathrm{V}}\left(\mu_{2}-\mathrm{O}\right)_{32}\left(\mathrm{O}_{t}\right)_{22}\right]^{6-}(\mathbf{6 a})$ with 3a. Color scheme: V, grey; $\mathrm{O}$, red; $\mathrm{Ti}$, blue; $\mathrm{Cl}$, green.

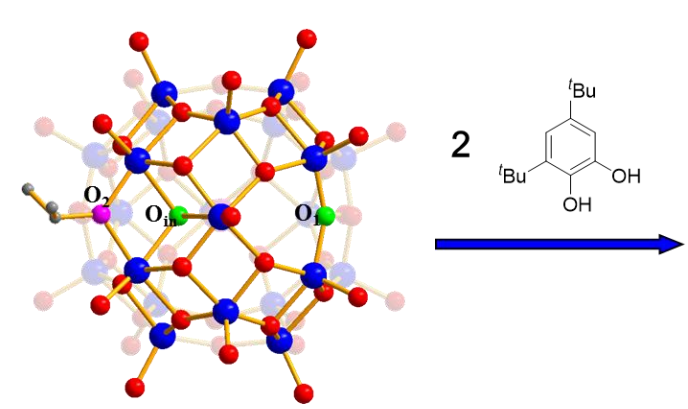

3a

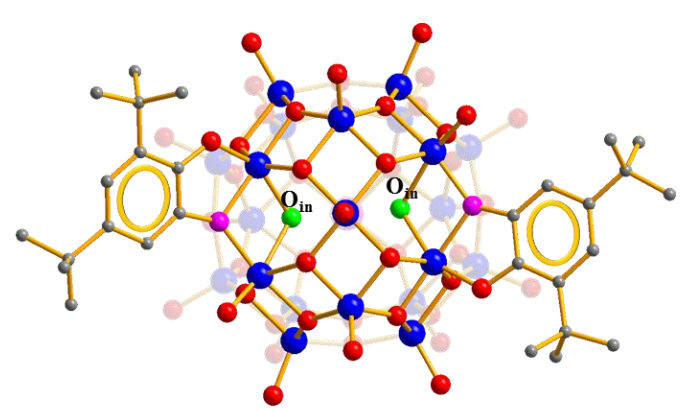

$4 a$

Figure S7. Reaction of 3a with two equivalents of $\mathrm{H}_{2} \mathrm{DTBC}$ to give $\mathbf{4 a}$ and three $\mathrm{HO}^{i} \mathrm{Pr}$. According to the geometrical analysis, during the ligand-exchange reaction, $\mathrm{O}_{\text {in }}$ of $\mathbf{3 a}$ is maintained in $\mathbf{4 a}, \mathrm{O}_{1}$ of $\mathbf{3 a}$ becomes $\mathrm{O}_{\text {in }}$ in $\mathbf{4 a}$, and $\mathrm{O}_{2}$ (note this atom belongs to an isopropoxide group) of $\mathbf{3 a}$ leaves as $\mathrm{HO}^{i} \mathrm{Pr}$. The protons at the $\mathrm{O}_{\text {in }}$ atoms (shown in green) are omitted for clarity.

\section{More description of compound 5.}

Cluster 5a, in the form $\left[\mathrm{I} @ \mathrm{Ti}_{22}\left(\mu_{2}-\mathrm{O}\right)_{11}\left(\mu_{3}-\mathrm{O}\right)_{20}\left(\mu_{1}-\mathrm{O}{ }^{i} \mathrm{Pr}\right)_{16}\left(\mu_{2}-\mathrm{O}^{i} \mathrm{Pr}\right)_{2}\left({ }^{t} \mathrm{BuCOO}\right)_{9}\left(\mathrm{OH}_{2}\right) \mathrm{H}_{3}\right]^{+}$, was derived by replacing five isopropoxide ligands of 3a with nine equivalents of pivalate. Yield is $49 \%$. The X-ray crystallography data and elementary analysis data have been included earlier. The three protons are added to balance the charge. Geometrical analysis suggests that $\mathrm{O} 1, \mathrm{O} 2$ inside the cage of $\mathbf{5 a}$ (see the figure immediately below) are derived from the $\mathrm{O}_{\text {in }}$ and one $\mu_{2}-\mathrm{O}$ in the shell of $\mathbf{3 a}$ (analogous to Figure S7). The pivalate are all $\mu_{2}$ - bridging bidentate ligands. 5a possesses only one symmetry element, i.e., a $\sigma$-plane. In this plane, a dangling $\mathrm{O}(\mathrm{O} 3)$ encapsulated by the cage is assigned as aqua ligand $\left(d_{\mathrm{Til}-\mathrm{O} 1}=2.20 \AA\right)$, rather than titanyl Ti=O. This assignment is further supported by FTIR (a sharp $v\left(\mathrm{OH}_{2}\right)$ at $\left.3666 \mathrm{~cm}^{-1}\right)$, BVS calculation and charge balance analyses. The $\mathrm{O} 1, \mathrm{O} 2$ atoms are probably not protonated, according to the BVS calculation. $\mathbf{5}$ readily dissolves in a variety of solvents, like $\mathrm{CHCl}_{3}$, acetone and isopropanol, and forms clear solutions. However, in ${ }^{1} \mathrm{H} \mathrm{NMR}$ spectra of $5 \mathbf{a}$ in $\mathrm{CHCl}_{3}$ (not shown herein), the signal of the $-\mathrm{OH}_{2}$ ligand in the shell was not observed. More 
work needs to be carried out to study the solution behavior of compound $\mathbf{5}$. The FTIR spectrum of compound $\mathbf{5}$ is provided as follows:
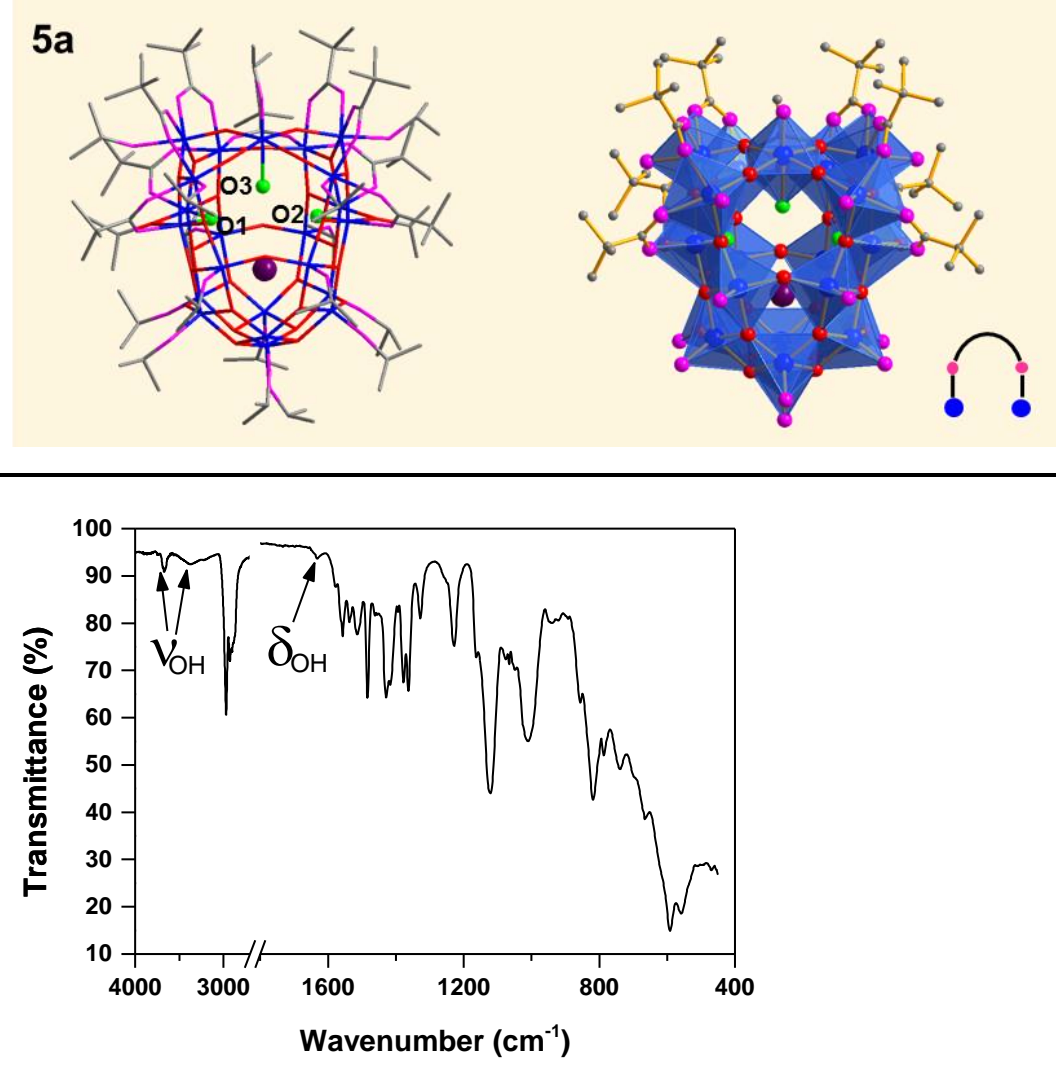

FTIR of compound $\mathbf{5}$ in solid form

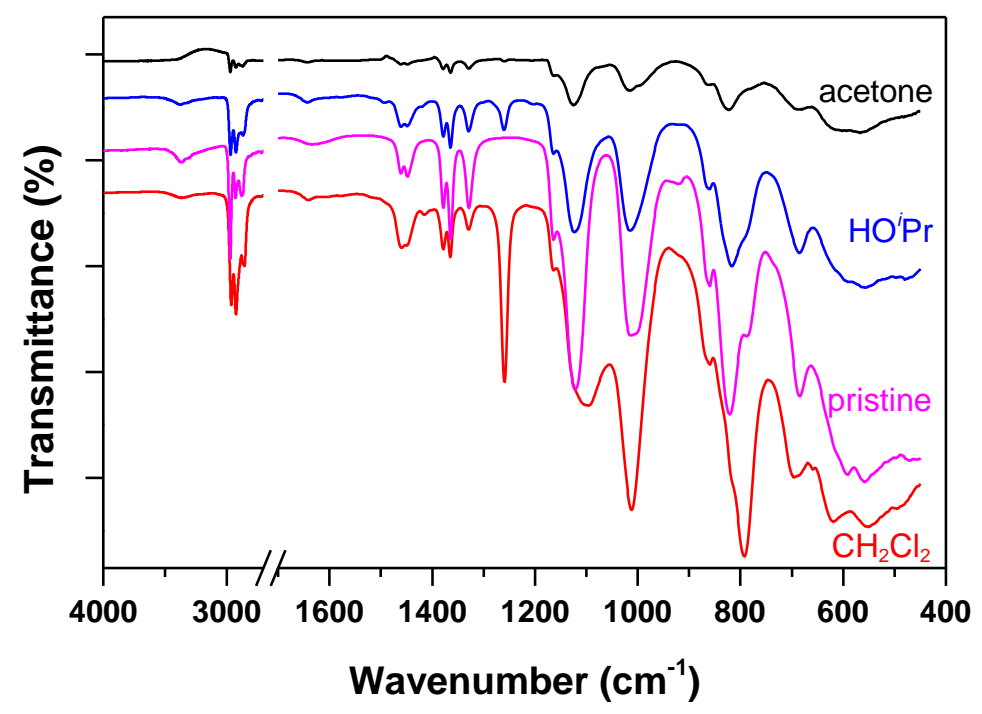

Figure S8. FTIR of compound $\mathbf{3}$ treated with various solvents. In order to examine the stability of $\mathbf{3}$ upon dissolution, 3 was dissolved in various solvents. After aging for 5 days, the solution was dried by air flow to give a solid for IR measurements. 


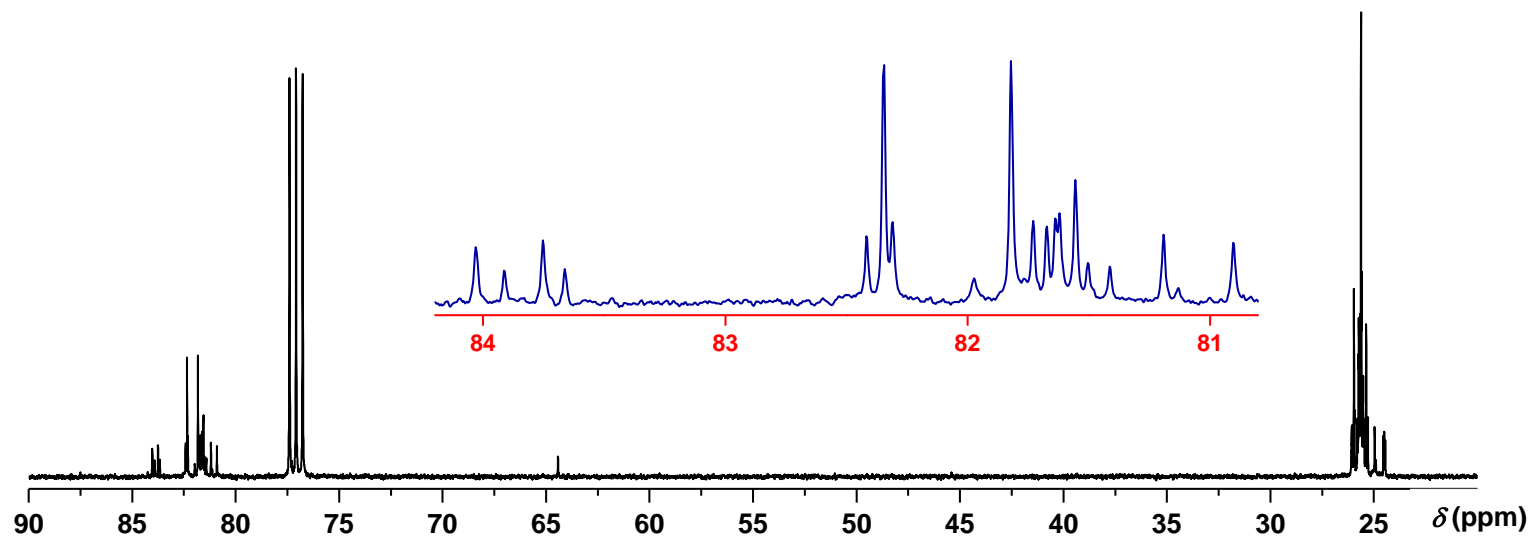

Figure S9. ${ }^{13} \mathrm{C}$ NMR of compound 3 in $\mathrm{CDCl}_{3}$.

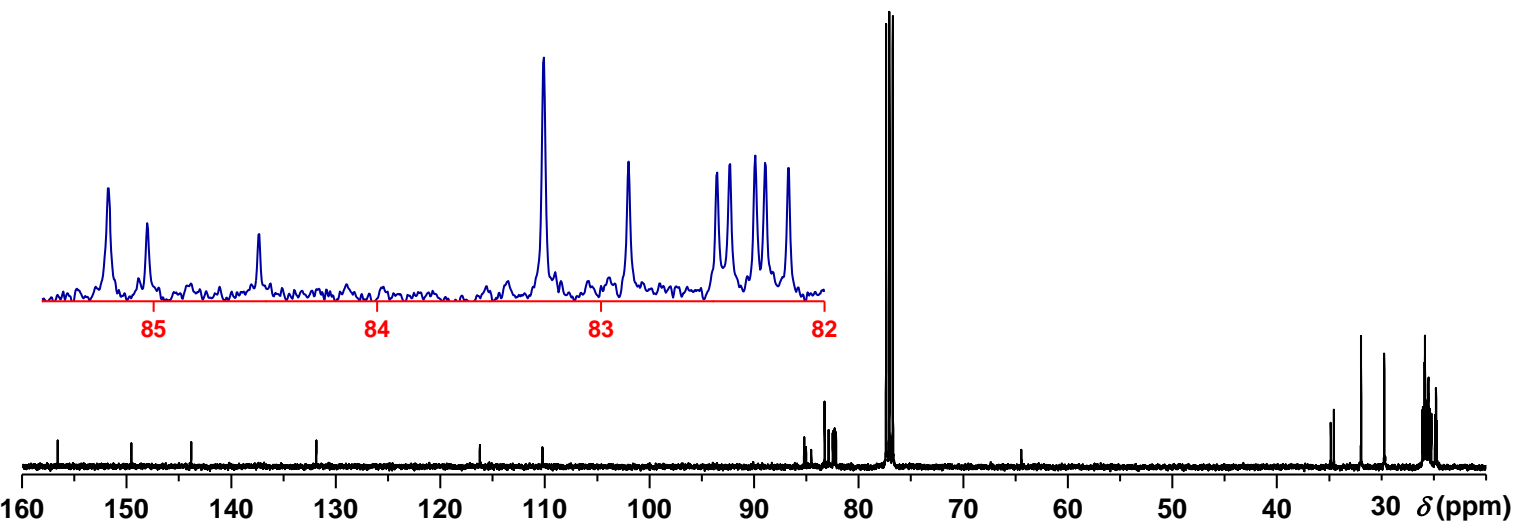

Figure S10. ${ }^{13} \mathrm{C}$ NMR of compound 4 in $\mathrm{CDCl}_{3}$.
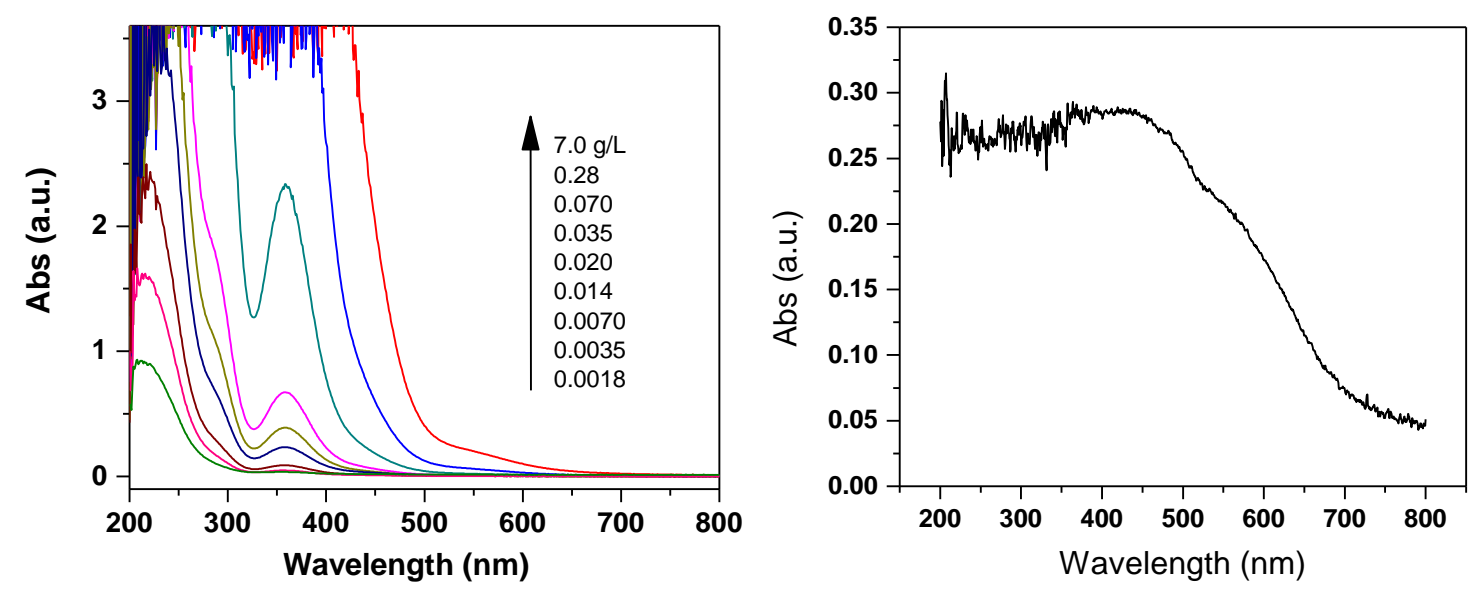

Figure S11. (Left) UV-vis of compound 3 in isopropanol and (right) diffuse reflectance spectrum in solid state. 

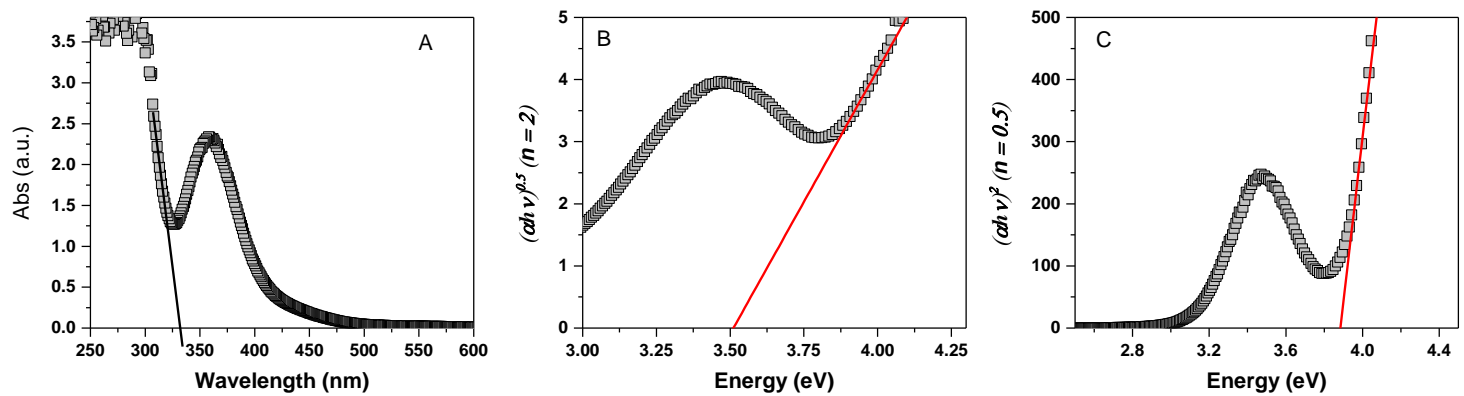

Figure S12. (A) UV-vis of compound $\mathbf{3}$ in isopropanol and (B and $\mathbf{C})$ calculations of the band gaps. According to the calculations using the literature method, ${ }^{4-5}$ the indirect HOMO-LUMO transition is ca. $3.51 \mathrm{eV}$, and the direct HOMO-LUMO transition is ca. $3.89 \mathrm{eV}$.

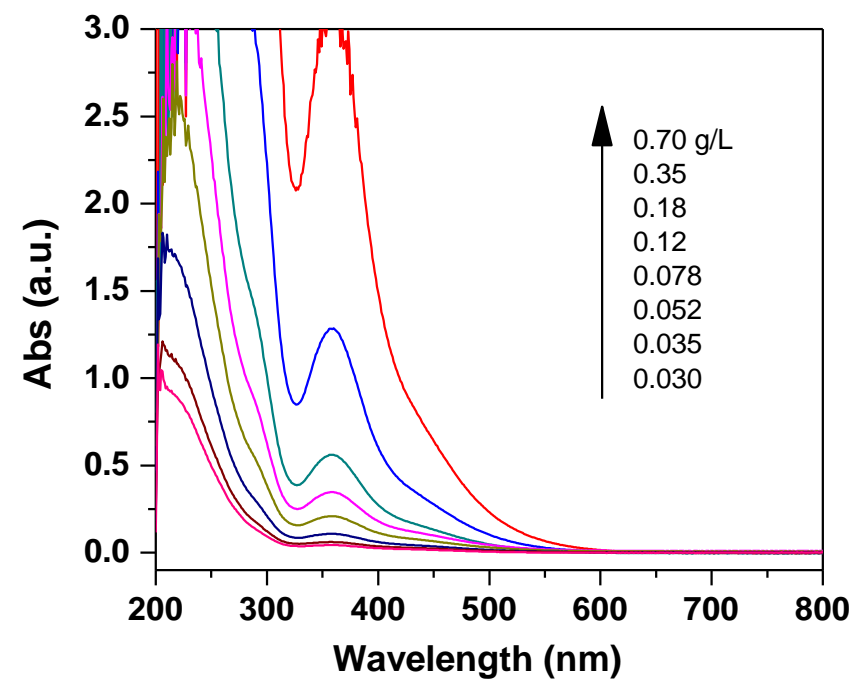

Figure S13. UV-vis of compound 4 in isopropanol.
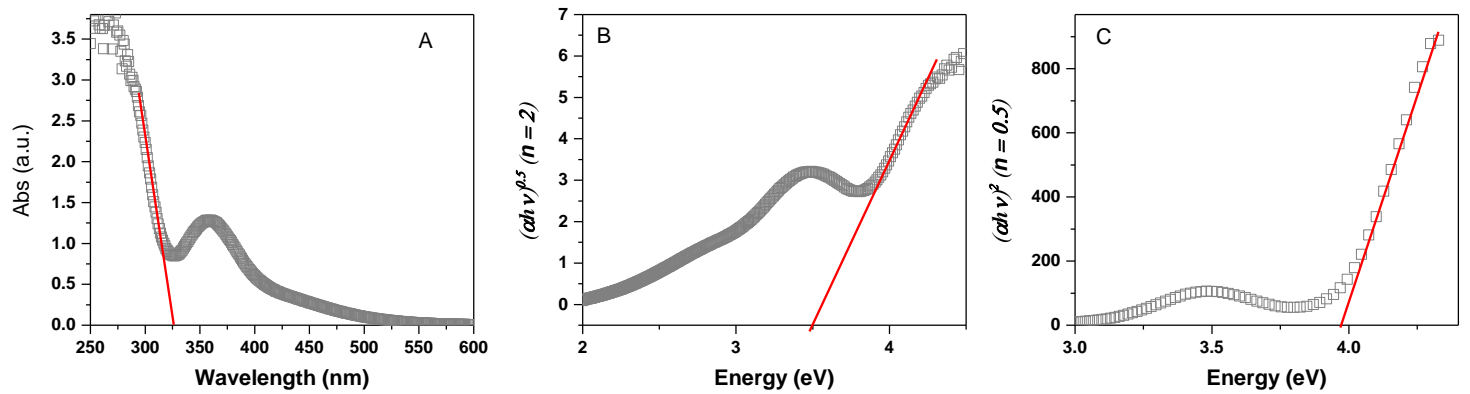

Figure S14. (A) UV-vis of compound 4 in isopropanol and (B and C) calculations of the band gaps. The indirect HOMO-LUMO transition is ca. $3.50 \mathrm{eV}$, and the direct HOMO-LUMO transition is ca. $3.97 \mathrm{eV}$.

4. Benedict, J. B.; Freindorf, R.; Trzop, E.; Cogswell, J.; Coppens, P., Large Polyoxotitanate Clusters: Well-Defined Models for PurePhase $\mathrm{TiO}_{2}$ Structures and Surfaces. J. Am. Chem. Soc. 2010, 132, (39), 13669-13671.

5. Benedict, J. B.; Coppens, P., The Crystalline Nanocluster Phase as a Medium for Structural and Spectroscopic Studies of Light Absorption of Photosensitizer Dyes on Semiconductor Surfaces. J. Am. Chem. Soc. 2010, 132, (9), 2938-2944. 